\title{
Improving the design of poppet valve in piston mud pump
}

\author{
Rima Yavdatovna Abdyukova \\ Ufa State Petroleum Technological University, \\ Branch of the University in the City of Oktyabrsky, Russian Federation \\ Abd_rima1968@mail.ru
}

\begin{abstract}
Research conducted in the oil field development facilitate formation of a system of fundamental knowledge that allows future specialist to scientifically analyze problems in their professional field, apply in practice the obtained basic knowledge, independently (with modern research methods) master the new information that they are to meet with during their business and scientific activities. Improving operational life of valve is still a serious problem. Thus, further research with the aim to find new design and process solutions to improve operational life of valves appear to be timely and attractive; it will allow improving technical and economic properties of mud pumps and those of drilling process as a whole.
\end{abstract}

Keywords - poppet valve wear, piston pump valve, valve plate, valve seat, valve packing, vibration monitoring.

\section{INTRODUCTION}

Operability of a piston pump is largely defined by its fluid end components: pistons, linear bushings, valves, packing. Under extreme operation conditions, the operational life of the fluid end components may amount to only several dozens of hours. One of important fluid end components of a pump is its valve. Thus, resolving issues in improving the operational life of the pump components, as well as their operability as a whole, is a timely issue [1].

\section{MATERIALS AND METHODS}

The objective of this research is to improve operational efficiency of piston mud pumps by improving the design of poppet valves by reducing dynamic loads occurring as a result of impact between the poppet and the valve seat. Currently, along with requirements for main operational parameters, economic efficiency and long operational life, piston pumps are subjected to additional requirements for low noise and vibration levels. One of vibration sources in the fluid end of a piston pump is its valve unit, whose increased vibration leads to premature wear, as well as to failure of pump components. To determine maximum loads transfered to the pump housing and their oscillating frequencies after the poppet hits the seat, some analytical research has been conducted [2]. Analytical model and equations modeling operation of a valve are given in Figure 1.

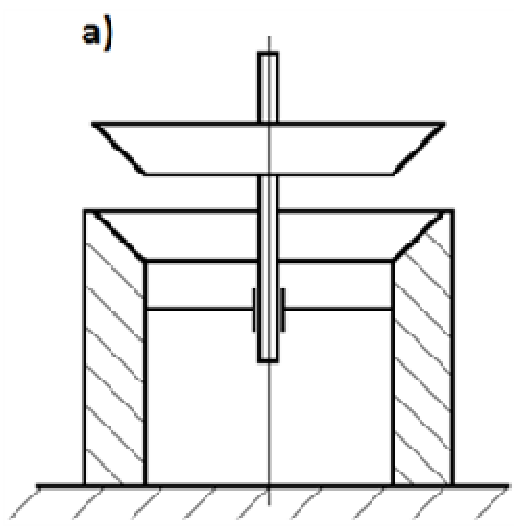

6)

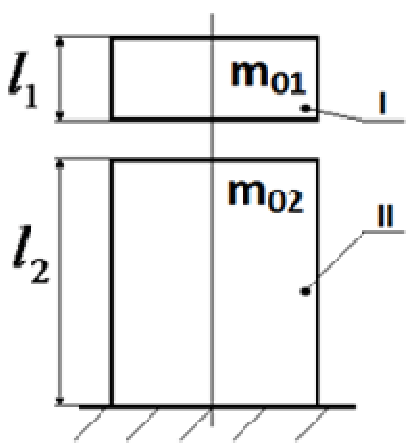

в)

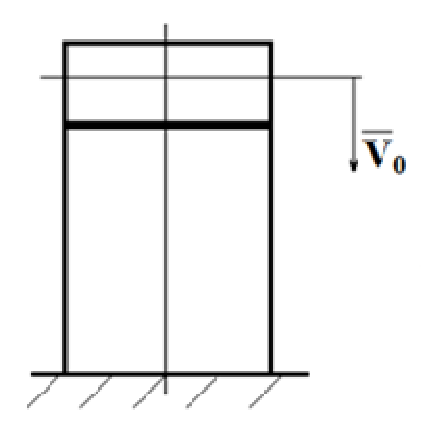

r)

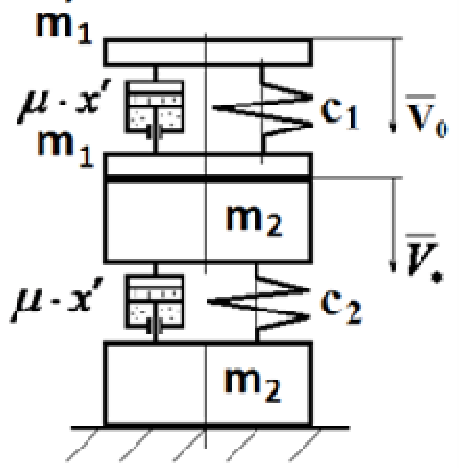

Fig. 1. Analytical model for modeling mud pump valve operation: I - poppet; II - seat.

$$
\begin{aligned}
& m_{1} x_{1}^{\prime \prime}=-c_{1}\left(x_{1}-x_{2}\right)-\mu\left(x_{1}^{\prime}-x_{2}^{\prime}\right) \\
& \quad\left(m_{1}+m_{2}\right) x_{2}^{\prime \prime}=-c_{2} x_{2}+c_{1}\left(x_{1}-x_{2}\right)-\mu x_{2}^{\prime}+ \\
& \mu\left(x_{1}^{\prime}-x_{2}^{\prime}\right)
\end{aligned}
$$

where $m_{1}, m_{2}$ are stem weights;

$x_{1}, x_{2}, x_{1}^{\prime}, x_{2}^{\prime}, x_{2}^{\prime \prime}, x_{2}^{\prime \prime}$ are coordinates, velocities and acceleration values of the objects respectively;

$\mu$ is drag coefficient;

$c_{1}$ and $c_{2}$ are stiffness coefficients of the stems;

$V_{0}$ is the initial velocity of stem I (in the moment of touchdown); 
$l_{1}$ and $l_{2}$ are stem lengths.

To reduce the forces transfered to the pump housing during the seating, we propose installing a special element made of elastic material between the seat and the pump housing. According to the theoretical data, a new valve design has been developed [3, 12], a diagram and separate elements of which are shown in Figure 2.

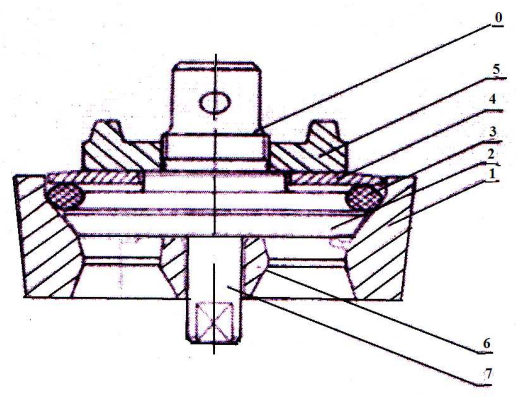

Fig. 2. New design of mud pump valve: 1 - valve seat; 2 - poppet; 3 packing ring; 4 - bushing; 5 - nut; 6 - crosshead; 7 - valve spigot; 8 -limiter.
Compared to the current version, forms of seating surfaces of the poppet, the seat and the packing ring has been changed. The seating surface of the seat is made in the form of a cone, transitioning to cylinder. The poppet has a form of a conical disk and when seated it bears against the cylindrical surface along the rubber packing ring, thus allowing reduction of impact between the poppet and the seat and providing valve tightness.

For experimental research of mud pump valve operation, a test stand was developed on the basis of 9MGr pump, complete with a measuring system [4]. A diagram of this test stand is shown in Figure 3.

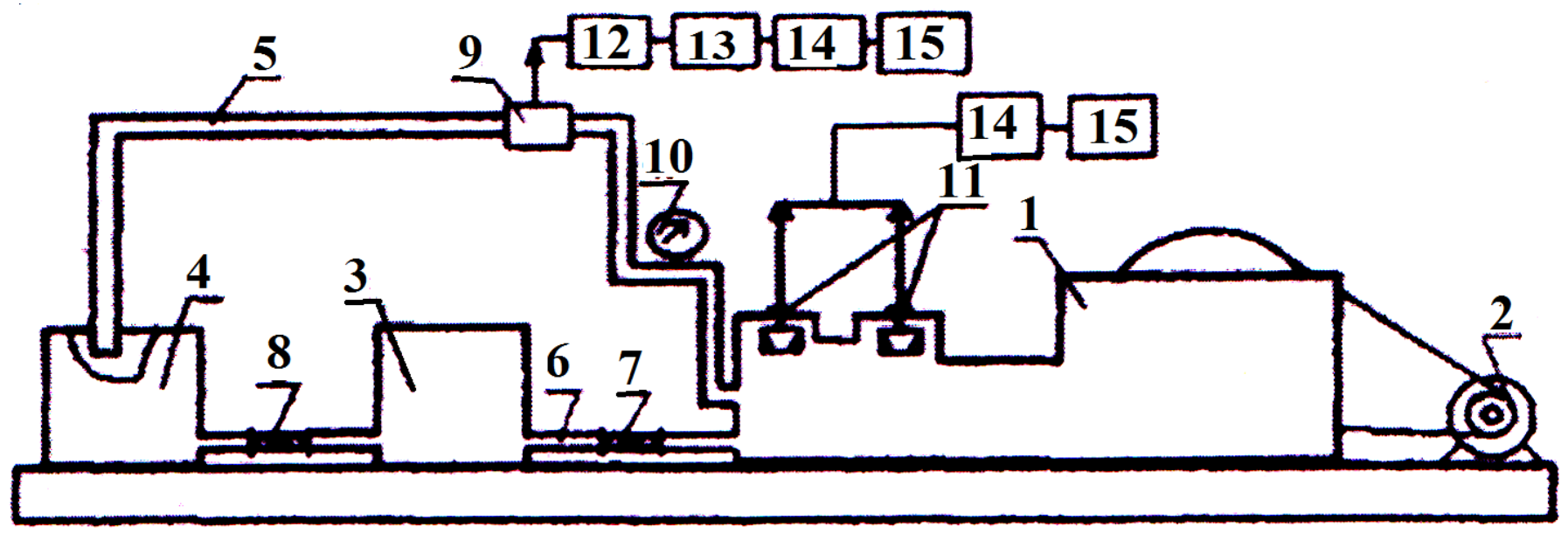

Fig. 3. Mud pump test stand with a measuring system: 1 - mud pump; 2 - motor; 3, 4- operating tanks; 5, 6- suction and discharge lines; 7, 8 - shut-off valves; $9-$ pressure $\quad$ transmitter; $10 \quad-\quad$ pressure $\quad$ gage; $11 \quad-$ transmitter; digital oscilloscope; 13 - computer; 14 - software; 15 - vibration meter.

The research revealed, that the proposed valve design allows reducing the impact of the poppet and the seat and provides valve tightness, however, vibration frequency of the housing increases. Presence of a flowing liquid layer exercise a damping effect, which in the end leads to appearance of lowfrequency vibration.

Due to that, the second variant of the mud pump valve has been developed. To dampen the vibration and reduce loads transfered to the pump housing from the impact between the poppet and the seat, we propose to install a special elastic element made of elastic material between the seat and the pump housing $[9,11]$. On the one hand, this element shall operate as a spring, reducing the magnitude of loads transfered to the pump housing and serving as a vibration isolator, and on the other hand, it will dampen the oscillations. Modeling diagram of valve operation with an elastic element between its seat and pump housing [5, 6], as well as relevant differential equations are shown in Figure 4. 


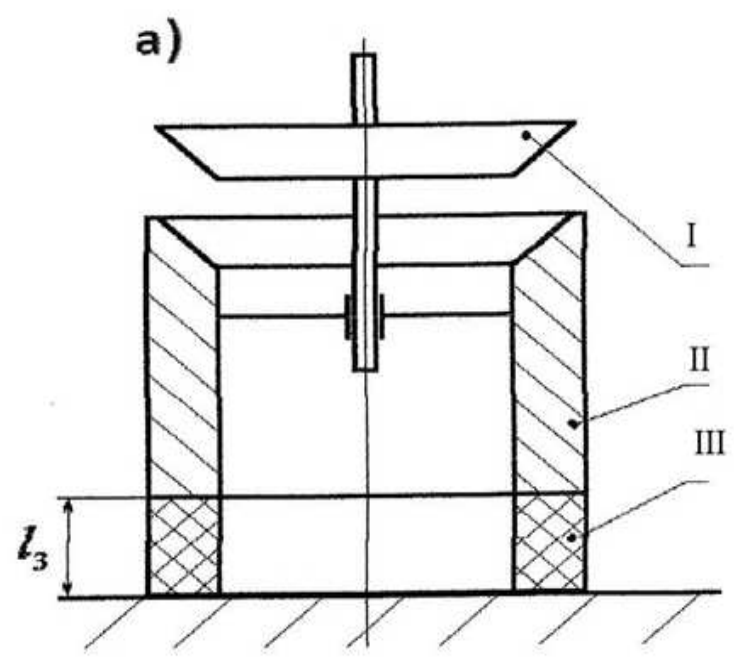

б)

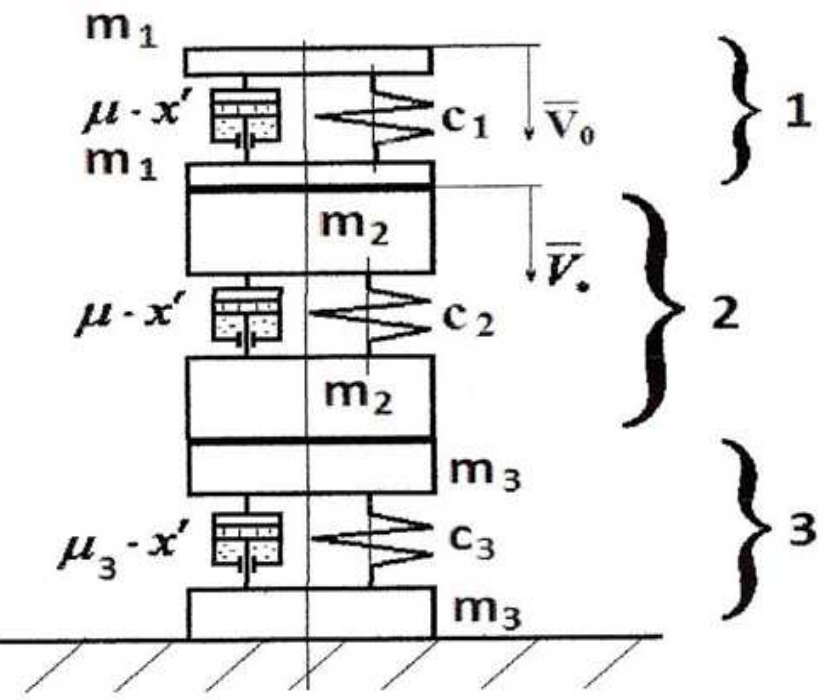

Fig. 4. Analytical model for modeling mud pump valve operation with an elastic element.

$$
m_{1} x_{1}^{\prime \prime}=-c_{1}\left(x_{1}-x_{2}\right)-\mu\left(x_{1}^{\prime}-x_{2}^{\prime}\right)
$$

$$
\left(n m_{1}+m_{1}\right) x_{2}^{\prime \prime}=-\frac{c_{1}}{n}\left(x_{2}-x_{3}\right)+c_{1}\left(x_{1}-x_{2}\right)-
$$$$
\mu\left(x_{2}^{\prime}-x_{3}^{\prime}\right)+\mu\left(x_{1}^{\prime}-x_{2}^{\prime}\right)
$$

$$
\left(\frac{n_{2} m_{1}}{\rho_{1} / \rho_{3}}+n m_{1}\right) x_{3}^{\prime \prime}=-\frac{c_{1}}{n_{2}\left(E_{1} / E_{3}\right)} x_{3}+\frac{c_{1}}{n}\left(x_{2}-x_{3}\right)-
$$$$
\mu_{3} x_{3}^{\prime}+\mu\left(x_{2}^{\prime}-x_{3}^{\prime}\right)
$$

where $\rho_{1}, \rho_{3}$ are density values of the poppet and the elastic element respectively;

$l_{3}$ is the height of the elastic element;

$m_{3}$ is the weight of the elastic element;

$E_{1}, E_{3}$ are values of the modulus of elasticity for material of the poppet and that of the elastic element;

$x_{3}, x_{3}{ }^{\prime}, x_{3}{ }^{\prime \prime}$ are coordinates, velocities and acceleration values of the elastic element;

$$
\begin{aligned}
& n=\frac{c_{2}}{c_{1}} ; \\
& n_{2}=\frac{l_{3}}{l_{1}} .
\end{aligned}
$$

Mechanical properties of materials that may be employed for vibration isolation are given in Table 1.

TABLE I. MECHANICAL PROPERTIES OF VIBRATION ISOLATION MATERIALS

\begin{tabular}{|c|c|c|c|c|}
\hline Material & $\begin{array}{c}\boldsymbol{E}_{\mathbf{3}}, \mathbf{M P a} \\
\left(\mathbf{1 0}^{\mathbf{5}}\right)\end{array}$ & $\begin{array}{c}\boldsymbol{\rho}_{\mathbf{3}}, \mathbf{~ k g} / \mathbf{m}^{\mathbf{3}} \\
\left(\mathbf{1 0}^{\mathbf{3}}\right)\end{array}$ & $\boldsymbol{E}_{\mathbf{1}} / \boldsymbol{E}_{\mathbf{3}}$ & $\boldsymbol{\rho}_{\mathbf{1}} / \boldsymbol{\rho}_{\mathbf{3}}$ \\
\hline $\begin{array}{c}\text { Fabric-based } \\
\text { laminate } \\
\left(\begin{array}{c}\text { PT, PTK, PT- } \\
\text { 1) }\end{array}\right.\end{array}$ & $0.059-0.098$ & $1.25-1.45$ & $35.59-21.43$ & $6.24-5.38$ \\
\hline PTFE 4 & $0.005-0.008$ & $2.1-2.3$ & $456.5-253.0$ & $3.71-3.39$ \\
\hline
\end{tabular}

Solution of the given differential equations has shown that the presence of the elastic element between the valve seat and the pump housing allow reducing the loads of the transfered loads and oscillation frequencies by an order of magnitude.

The valve design with an elastic element in the form of a thick washer installed between the valve seat and the pump housing $[7,10]$ is shown in Figure 5.

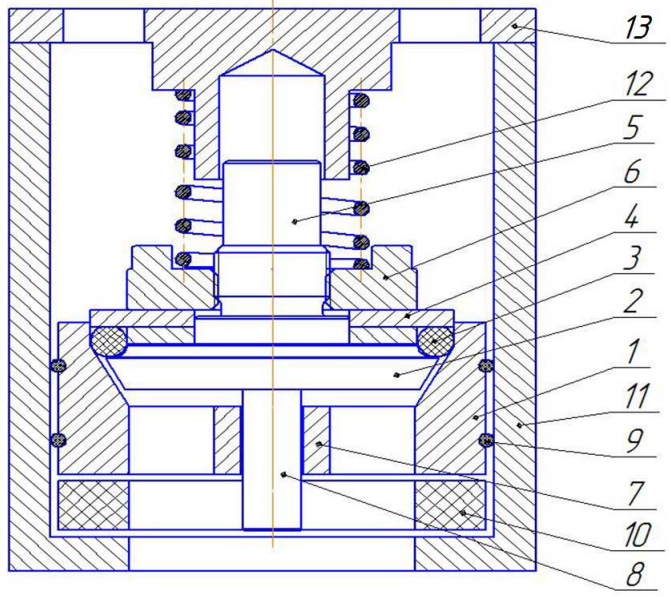

Fig. 5. New valve design with an elastic element: 1 - valve seat; 2 - poppet; 3 - packing ring; 4 - bushing; 5 - limiters; 6 - nut; 7 - crosshead; 8 - valve spigot; 9 - packing seats; 10 - elastic element; 11 - pump housing; 12 spring; 13 - valve cap.

During the operation, an impact wave arising from seating the poppet to the seat is transfered to the elastic element that serves as a spring. Due to low rigidity of the element, vibration of the pump housing is reduced and as a result, operational efficiency of the pump as a whole improves. Testing of the developed valve at the test stand confirmed a significant reduction in vibration frequency and impact loads [8], shown in Table 2. 
TABLE II. AMPLITUDE AND FREQUENCY OF THE PUMP HOUSING OSCILLATIONS

\begin{tabular}{|c|c|c|c|c|c|c|}
\hline \multirow{4}{*}{$\begin{array}{l}\text { Frequency } \\
\text { range of the } \\
\text { oscillations, } \\
\text { Hz }\end{array}$} & \multirow{3}{*}{\multicolumn{2}{|c|}{$\begin{array}{c}\text { Mass } \\
\text { production } \\
\text { valve }\end{array}$}} & \multicolumn{4}{|c|}{ Developmental prototype of the valve } \\
\hline & & & \multirow{2}{*}{\multicolumn{2}{|c|}{$\begin{array}{c}\text { Russian Patent no. } \\
41825 \\
\text { highest frequencies in } \\
\text { the range, } \mathrm{Hz} \text { and } \\
\text { micron }\end{array}$}} & \multirow{2}{*}{\multicolumn{2}{|c|}{$\begin{array}{l}\text { Russian Patent no. } \\
110158 \\
\text { highest } \\
\text { frequencies in the } \\
\text { range, Hz and } \\
\text { micron }\end{array}$}} \\
\hline & & & & & & \\
\hline & 15 & 1.8 & & & & \\
\hline $30-60$ & 35 & 2.5 & & & & \\
\hline $60-90$ & 14 & 1.7 & & & & \\
\hline $90-130$ & 110 & 2.46 & & & & \\
\hline $60-120$ & & & 100 & 12 & & \\
\hline $280-350$ & & & 198 & 1.65 & & \\
\hline $500-600$ & & & 546 & 1.7 & & \\
\hline $780-999$ & & & 820 & 1.31 & & \\
\hline $60-120$ & & & & & 118 & 1.9 \\
\hline $180-360$ & & & & & 200 & 0.8 \\
\hline $540-600$ & & & & & 500 & 0.6 \\
\hline $720-900$ & & & & & 550 & 0.4 \\
\hline
\end{tabular}

\section{CONCLUSION}

The results of the research:

1. Maximum value of loads and their frequencies transfered from the valve to the pump housing depend on the value of the modulus of elasticity of the valve component materials. When the ratio between Young's elasticity values of the poppet and the elastic element is higher than 100, maximum loads transfered to the pump housing reduce significantly.

2. A technical solution is proposed, allowing reducing the values of the loads transferred to the pump housing when the poppet is seated to the valve seat.

3. Experimental research performed at the specially developed test stand has shown, that increase in the oscillation frequencies allows reducing maximum amplitude of vibration on average by $16 \%$ compared to the amplitude of massproduced valves.

4. The experimental research of the developed valve with changes in design allowed establishing that a shock-free seating of poppet to the seat is achieved and overall operational efficiency of the mud pump increases.

\section{References}

[1] R.Y. Abdyukova and M. S. Gabdrahimov, "Laboratory test stand valve piston pumps," Oil \& Gas Journal, 2001, p. 405.

[2] M.Ya. Khabibullin, R.I. Suleimanov, D.I. Sidorkin and I.G. Arslanov, "Parameters of Damping of Vibrations of Tubing String in the Operation of Bottomhole Pulse Devices," Chem. Petrol. Eng., vol. 53, pp. 378-384, 2017. https://doi.org/10.1007/s10556-017-0350-6

[3] A.V. Lyagov, M.S. Gabdrakhimov, A.S. Galeev, B.Z. Sultanov and G.S. Ramazanov, "Rilling wells with the use of outside multistage vibro exhibitors," Oil industry, 1990, № 4, pp. 12-15.

[4] A.V. Lyagov, B.Z. Sultanov and M.S. Gabdrakhimov, "Multistanded multistage vibrator hydraulic,” Oil industry, 1990, № 4, pp. 41-43.

[5] N.Y. Golovina, L.G. Akhmetov, A.N. Vikharev and I.G. Arslanov, "Analysis on compressor blading conditions of helicopter's gas-Turbine engine working in polluted environment," International Journal of Applied Engineering Research, vol. 12, pp. 293-296, 2017.
[6] R.R. Shangareev "Relevance of assessment science research concerning occupational hazards of drilling operations," Ecology, Environment and Conservation Paper, vol. 21, pp. 175-180, 2015.

[7] A.C. Aplin and J.H.S. Macquaker, "Mudstone diversity: origin and implications for source, seal, and reservoir properties in petroleum systems," pp. 2031-2059.

[8] N. Clauer, F. Jourdan and H. Zwingmann, "Dating petroleum emplacement by illite40ar/39 ar laser stepwise heating: discussion," AAPG Bulletin (American Association of Petroleum Geologists), vol. 95, № 12, pp. 2107-2111, 2011.

[9] H.S. Shi, J.B. Yun and H.N Qiu, "Dating petroleum emplacement by illite40ar/39ar laser stepwise heating: reply," AAPG Bulletin (American Association of Petroleum Geologists), vol. 95, № 12, pp. 2112-2116, 2011.

[10] V.P. Golub, Y.V. Pavlyuk, P.V. Fernati, "Determining parameters of fractional-exponential heredity kernels of nonlinear viscoelastic materials," International Applied Mechanics, vol. 53, № 4, pp. 419-433, 2017.

[11] A.E. Griffiths, V.R. Begliarbekov, M.A. Shakbazov, P. Sultanov, "Increasing production from old, onshore oil fields, azerbaijan- a case study,” Petroleum Geoscience, vol. 7, № 1, pp. 65-73, 2001.

[12] S. Hara, Y. Yamada, K. Ito and Y. Morita, "A vibration control method for power-assisted moving vibration systems," IEEJ Transactions on Electrical and Electronic Engineering, Vol. 6-2, pp. 190-192, 2011. 